\title{
WisDOT Case Examples Using SPMs
}

\section{January 27, 2016}

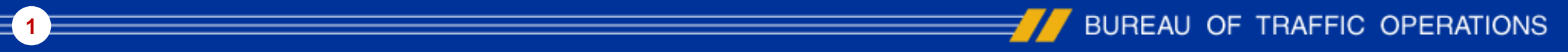




\section{Agency Factoids - WisDOT}

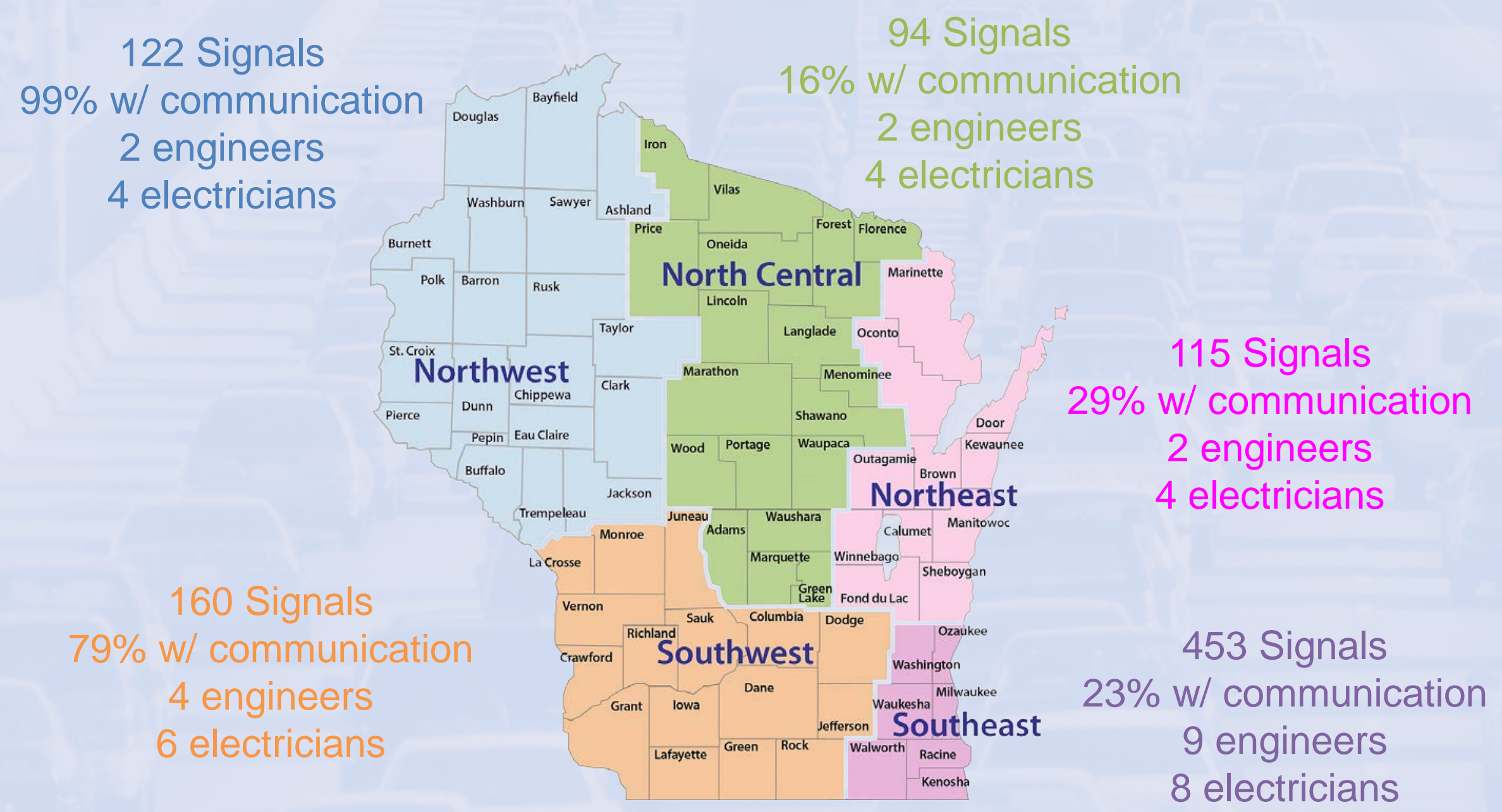

Approximately 950 signals statewide with communication to 400 of the signals. - 50\% fiber \& $50 \%$ cellular 


\section{Agency Factoids - Systems}

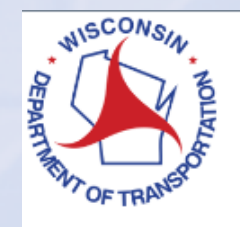

Signal Performance Metrics

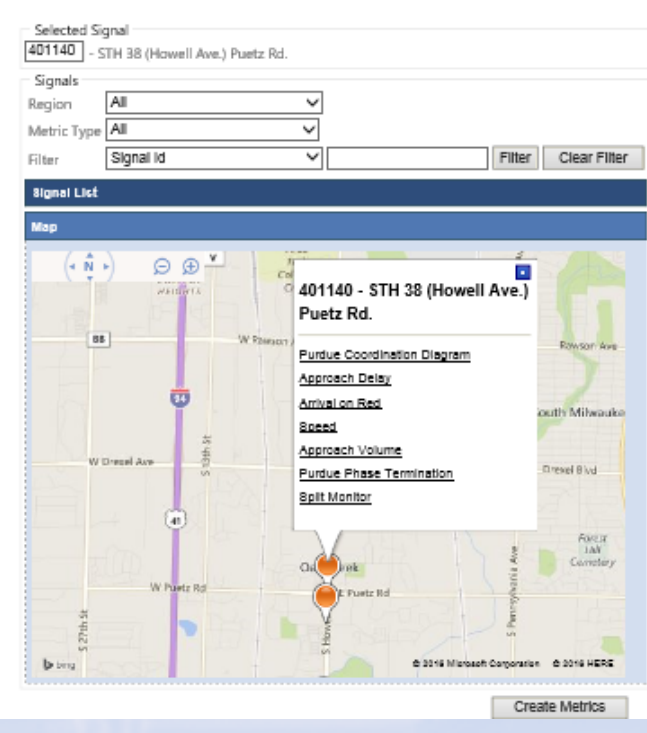

- Deployed UDOT Signal Performance Metrics

- 170 intersections collecting high resolution data*

\section{TACTICS ${ }^{\mathrm{TM}}$}

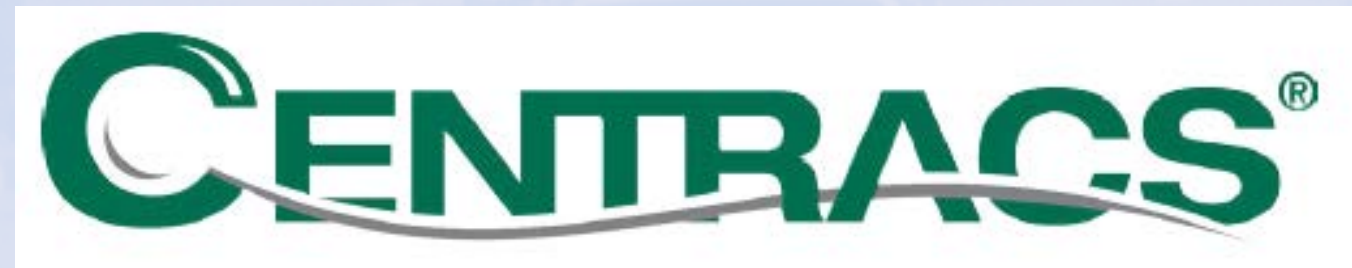




\section{Agency Factoids - Detection \& PreEmption}

- Stop Bar Detection (left turns and side street)

$-6^{\prime} \times 20^{\prime}$ typical

- Dilemma zone detection on the mainline and high speed side streets

- Regional variances in layout/design

- Loop, Video and Microwave all used

- Regional Preference

- Use Lane Group Detection

- Considering shift to Lane by Lane for performance measures

- Loops typically numbered such that first digit indicates phase it is associated with

- Detection failures are identified by our travelling public

- EVP is installed upon request (approx. 30\% currently)

- Railroad Preemption at approximately 24 state owned signals 


\section{WisDOT Experience}

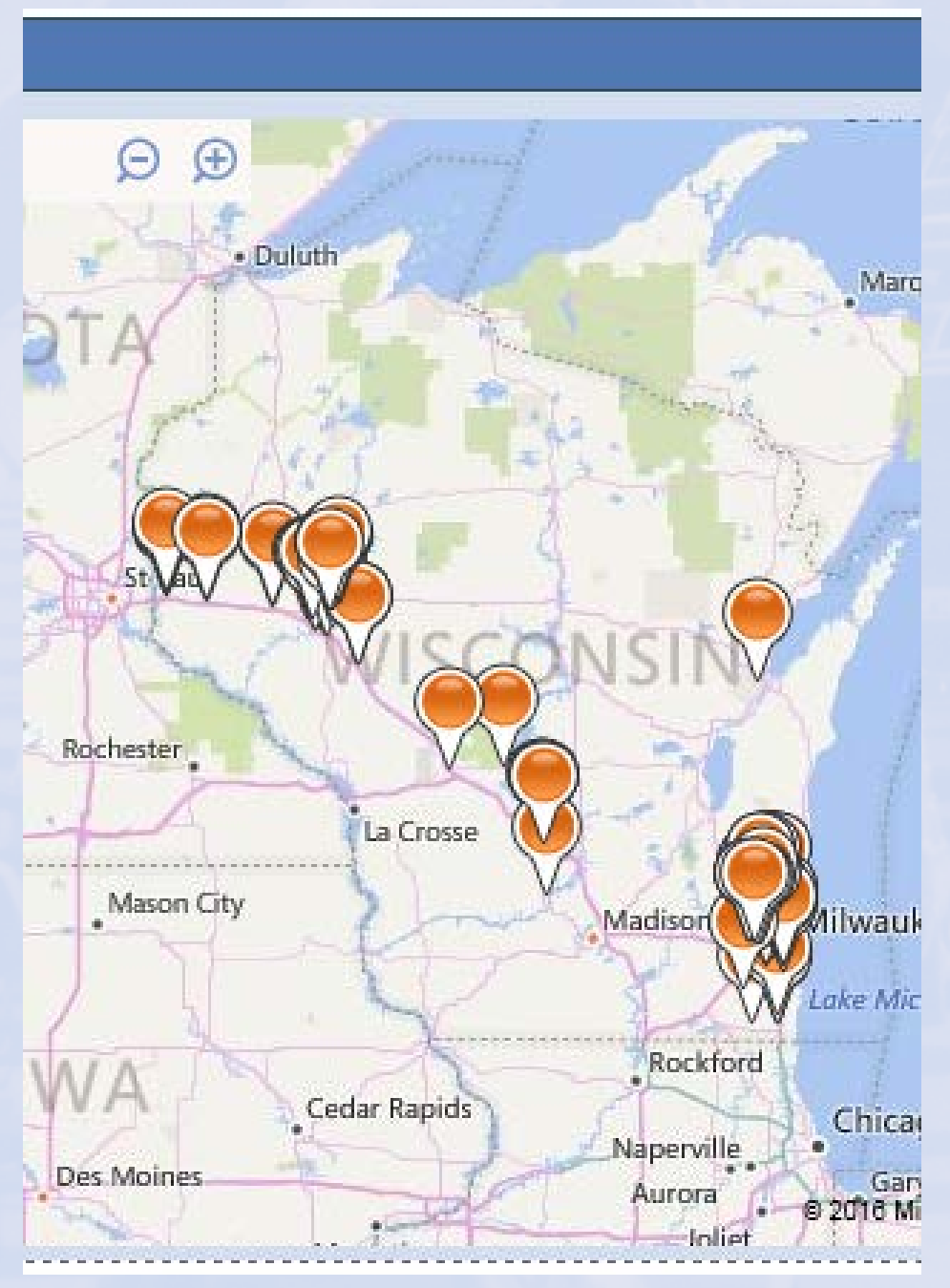

- Nov 2014 - IT project approved

- May 2015 - Test intersections were added

- July 2015 - Test intersections communicating with system and additional intersections (ASC3s with fiber) added

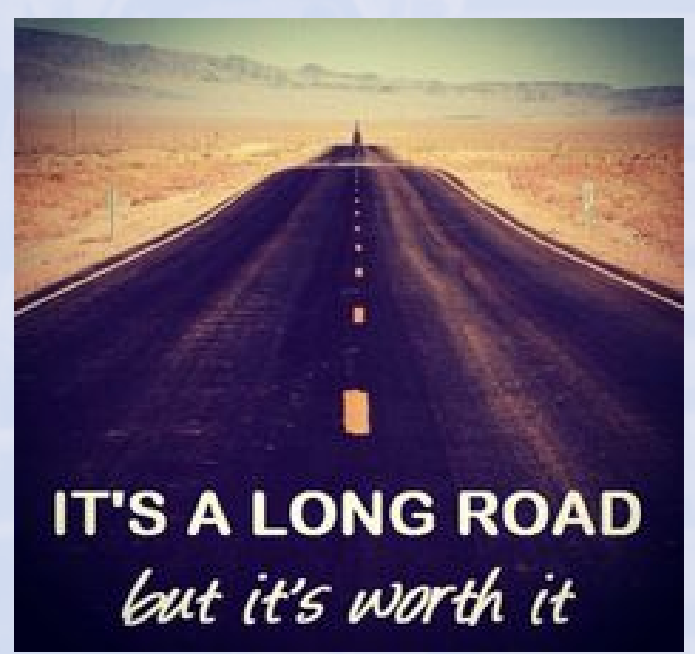




\section{WisDOT Next Steps}

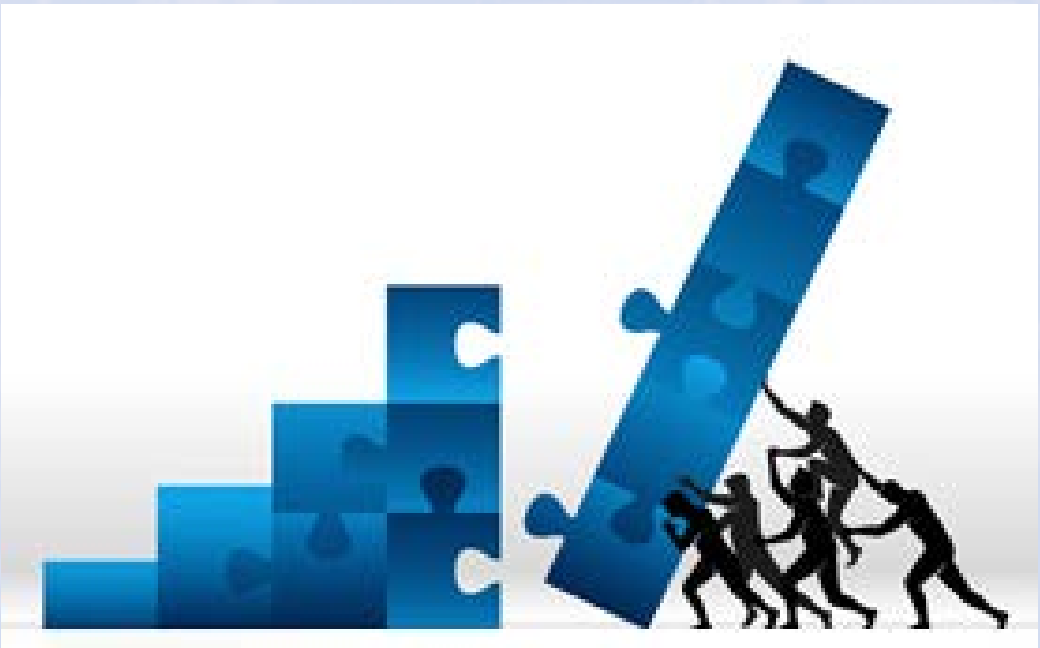

- Add EPAC intersections on fiber to SPM system

- Create alarms/reports

- Figure out how to get data via cellular modems

- Work with our IT staff on storage space issues

- Make sense of adaptive system performance metrics

- Continue to add remote detection to the remaining signals

- Develop operations based performance measures 


\section{In the Meantime...}

Identifying Detection Issues using Phase Termination Diagram

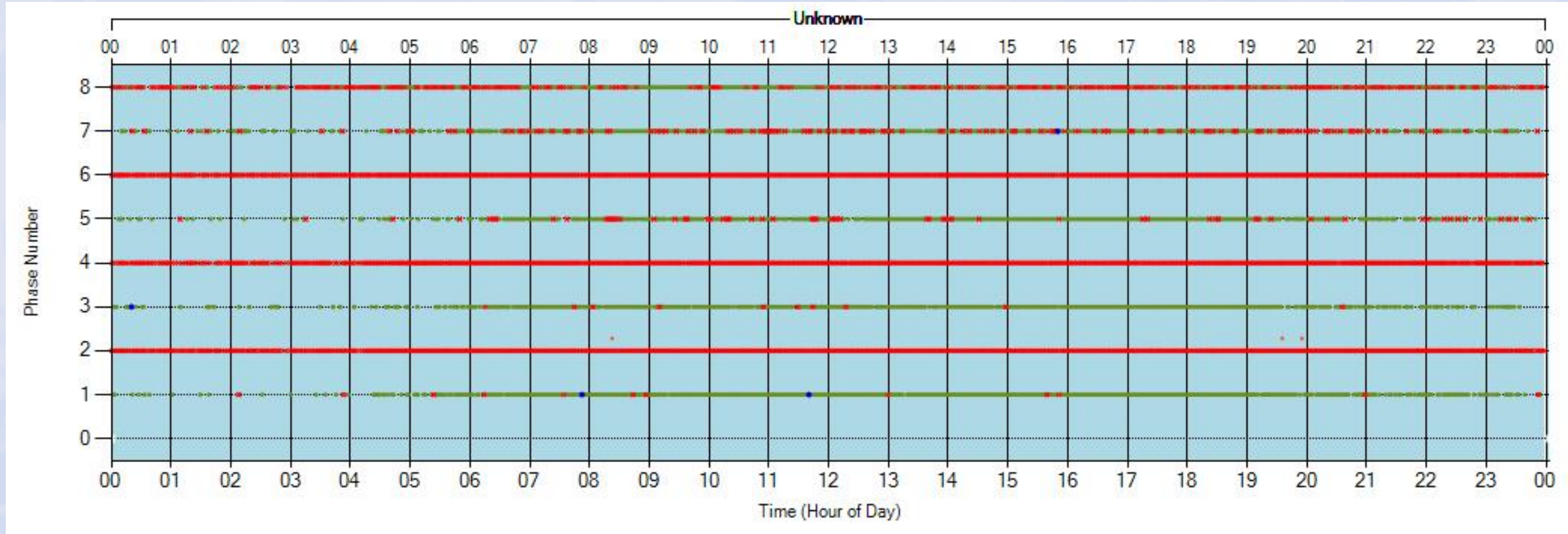

*Video Detection Incorrectly Mapped 


\section{In the Meantime...}

\section{Identifying Issues using Phase Termination Diagram $\&$ Split Monitor}

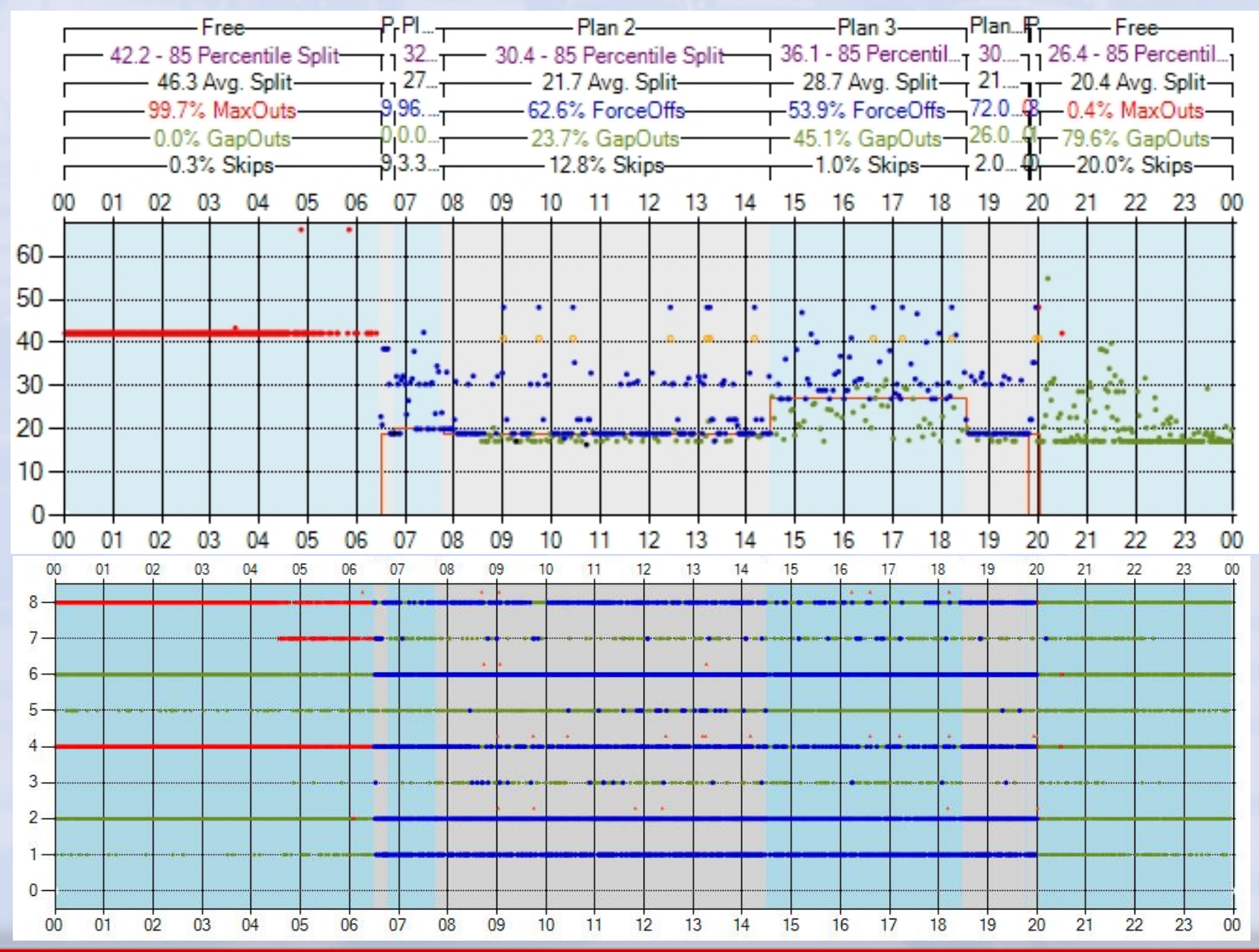




\section{In the Meantime...}

\section{Identifying Issues using Purdue Coordination Diagram}

\& Phase Termination Diagram

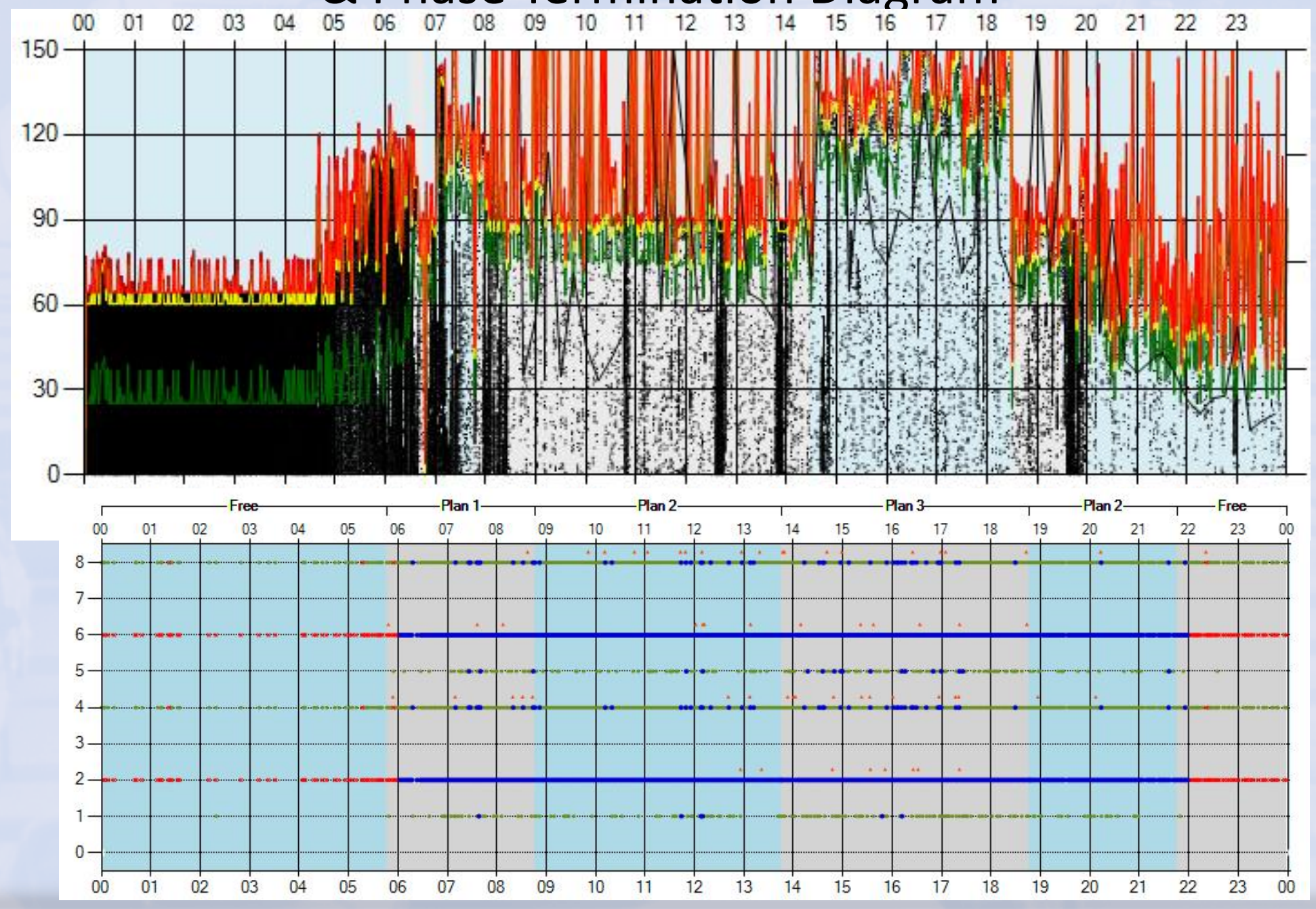




\section{In the Meantime...}

\section{Identifying Short Splits with Split Monitor}

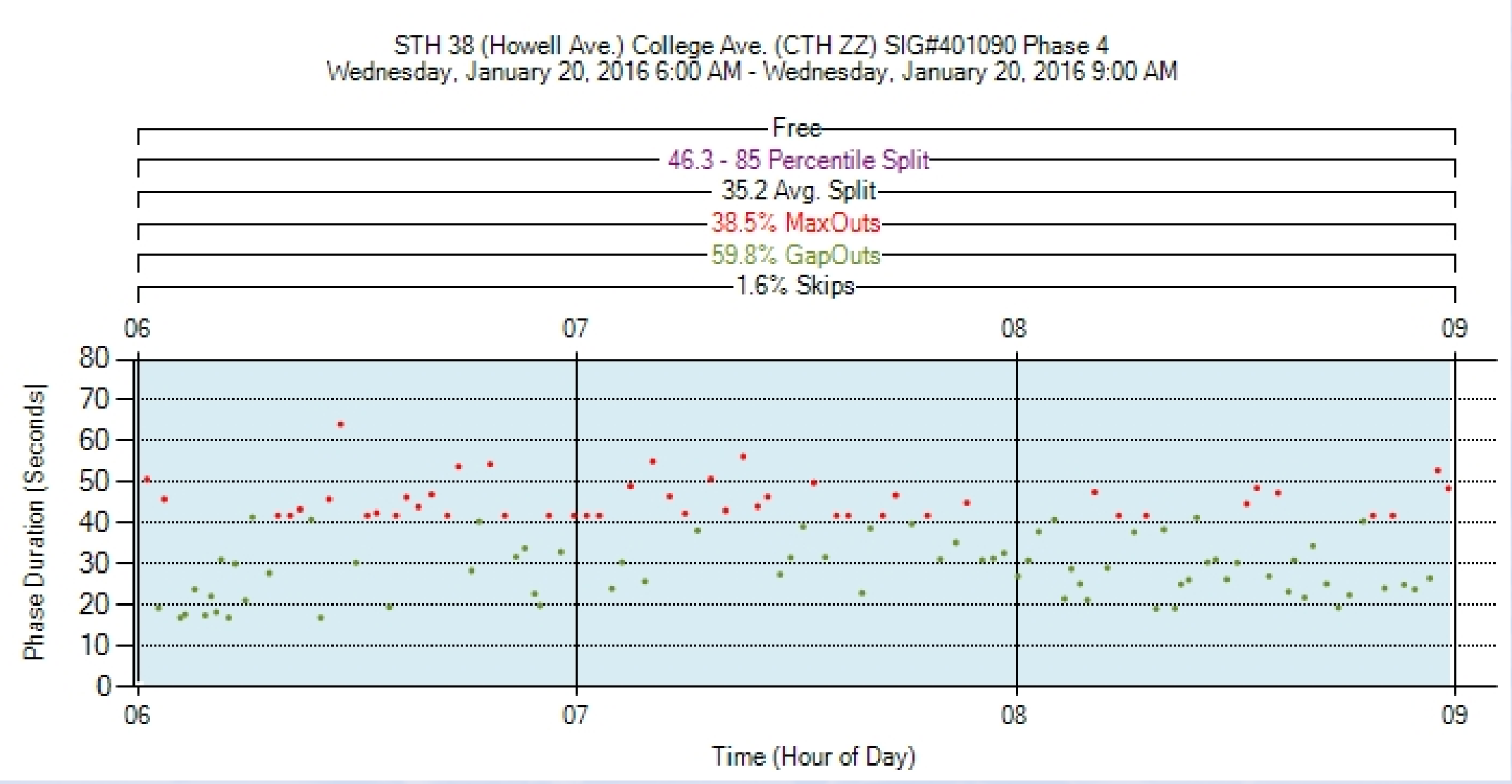




\section{In the Meantime...}

\section{Identify Issues with Adaptive System}

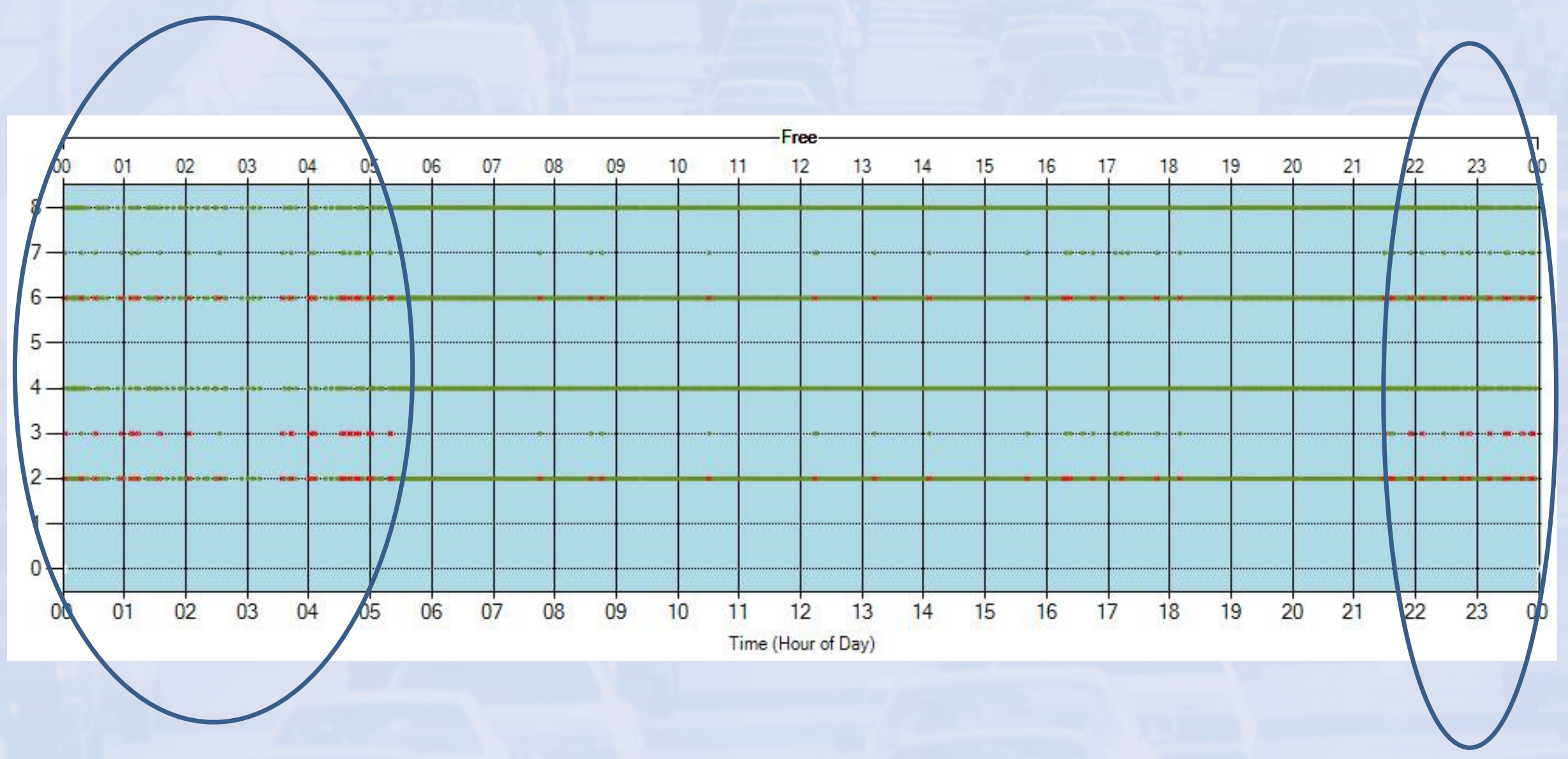




\section{Questions? \\ Joanna Bush, PE \\ Statewide Traffic Signal Systems Engineer joanna.bush@dot.wi.gov (608) 261-5845}

